\title{
Relationship between microaspiration of gastric contents and ventilator-associated pneumonia
}

\author{
Anahita Rouzé ${ }^{1}$, Emmanuelle Jaillette ${ }^{1}$, Saad Nseir ${ }^{1,2}$ \\ ${ }^{1}$ Critical Care Center, R. Salengro Hospital, University Hospital of Lille, boulevard du Pr Leclercq, Lille cedex, France; ${ }^{2}$ Medical School, Lille \\ University, Place de Verdun, Lille, France \\ Correspondence to: Prof. Saad Nseir. Critical Care Center, R. Salengro Hospital, University Hospital of Lille, boulevard du Pr Leclercq, 59037 Lille \\ cedex, France. Email: s-nseir@chru-lille.fr.
}

Submitted Jul 26, 2018. Accepted for publication Jul 30, 2018.

doi: $10.21037 / \mathrm{atm} .2018 .07 .36$

View this article at: http://dx.doi.org/10.21037/atm.2018.07.36

\section{Incidence of microaspiration of gastric contents}

Aspiration of gastric contents is common in critically ill patients, and has been identified as a risk factor for ventilator-associated pneumonia (VAP). A prospective multicenter study, using pepsin as a marker of microaspiration of gastric content reported that $88.9 \%$ of the 360 included patients experienced at least one episode of microaspiration (1). However, in many patients this event is not followed by any negative impact on patient outcome. The recent multicenter BestCuff study reported that $67 \%$ of patients had abundant microaspiration of gastric contents, defined by the presence of pepsin in at least $30 \%$ of tracheal aspirates (2).

\section{Pathophysiology and diagnosis of gastric content microaspiration}

Microaspiration of contaminated oropharyngeal and gastric secretions around the tracheal cuff is the main route of entry of bacteria into the lower respiratory tract in intubated critically ill patients. Bacterial growth in the stomach of critically ill patients is favored by enteral nutrition, alkalization of gastric contents, and the presence of bilirubin in gastric secretions. Tracheobronchial colonization could progress to VAP when the quantity and virulence of bacteria are high. Local and general host defences also play an important role in the transition from colonization to VAP. Progression of secretions from the space above the cuff into the lower respiratory tract depends on mechanical ventilation, tracheal tube, enteral nutrition, and patient-related factors (3) (Figure 1).

The gold standard for diagnosing microaspiration of gastric contents is technetium $99 \mathrm{~m}$. However, the use of this radioactive marker is not allowed in the ICU, and patients have to be transferred to the radiology department to perform the diagnosis. However, intrahospital transport of critically ill patients is associated with considerable potential for misadventure, and could be a life threatening endeavor. Further, transport of critically ill patients outside the ICU has been identified as a risk factor for VAP. Recently, the presence of pepsin in tracheal secretions has been suggested as a marker for microaspiration of gastric contents in critically ill patients $(1,4)$. This marker is easy to use in routine in critically ill patients. However, its short window of detection (2-3 h after an aspiration event) is the main limitation.

\section{Pulmonary consequences of microaspiration}

The potential negative impact of microaspiration of gastric contents is related to the presence of bacteria in these secretions, and to the direct lesions caused by gastric juice. In fact, gastric juice of critically ill patients is proinflammatory, and stimulates human pulmonary cells in vitro, resulting in increased histologic damage (5).

The role of the stomach in the pathogenesis of VAP has been a matter for debate. Several studies identified the bacteria responsible for VAP in gastric contents, suggesting a causal role for microaspiration of gastric contents. A randomized controlled study compared the impact of antacid, ranitidine, or sucralfate on gastric 


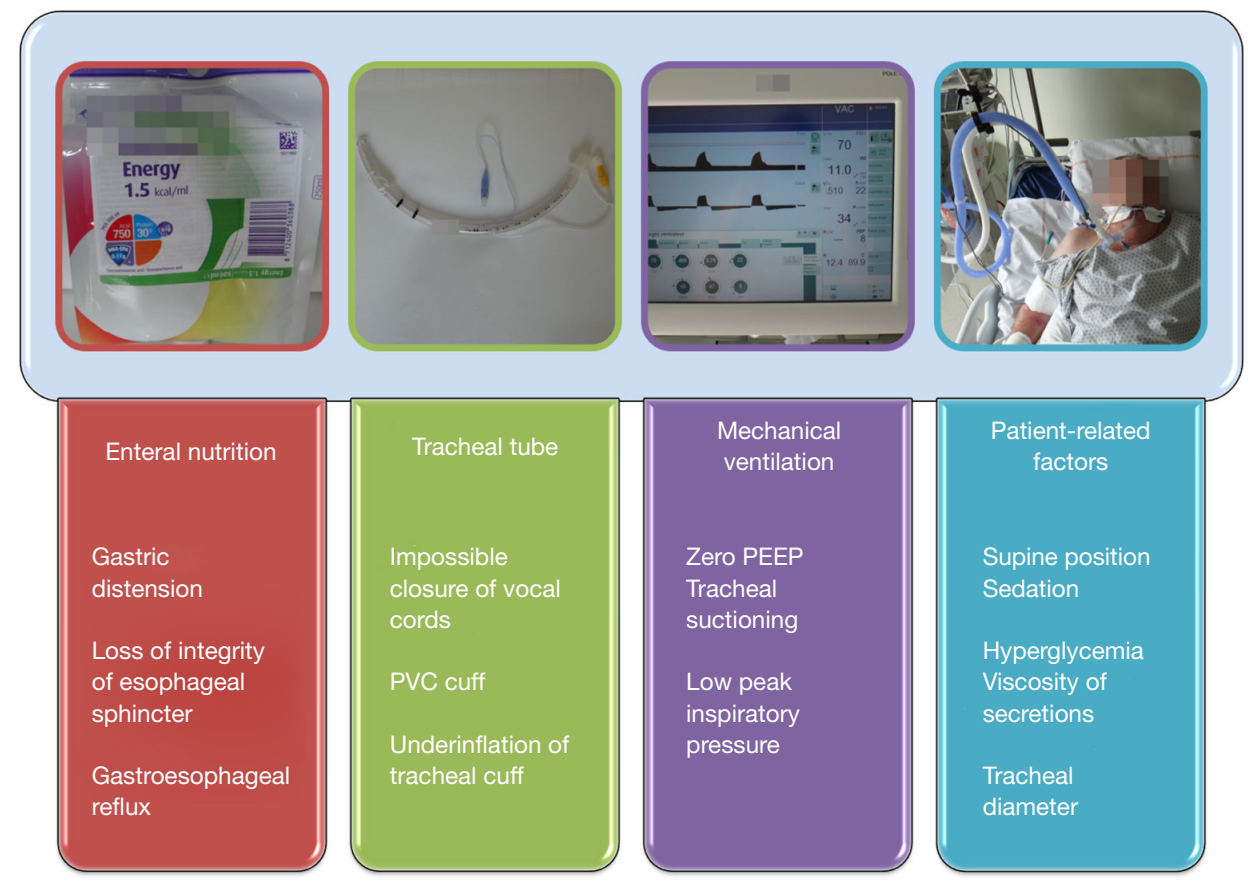

Figure 1 Risk factors for microaspiration of gastric contents in critically ill patients. PVC, polyvinyl chloride; PEEP, positive end-expiratory pressure.

bleeding, bacterial colonization, and VAP in a cohort of 244 patients (6). Whilst gastric bleeding incidence was not different between the three groups, patients who received sucralfate had significantly lower median gastric $\mathrm{pH}$, gastric colonization, and late-onset VAP rates. Interestingly, using molecular typing $84 \%$ of patients with late-onset VAP related to Gram negative bacteria had gastric colonization with the same bacteria before VAP occurrence. Further indirect evidence of the role of the stomach in the pathogenesis of VAP came from observational studies (7), and from randomized controlled studies evaluating the impact of systemic digestive decontamination, semirecumbent position, or continuous control of cuff pressure on VAP incidence $(4,8,9)$. Metheny and colleagues (1) performed a prospective study to determine the impact of abundant microaspiration of gastric contents on VAP incidence. Pepsin was measured in 6,000 tracheal aspirates, coming from 360 intubated patients receiving enteral nutrition. Abundant microaspiration was independently associated with VAP occurrence. Other independent risk factors included deep sedation, and neuromuscular blocking agent use.

However, the above-discussed studies have important limitations. In addition, several studies did not confirm the role of the stomach in the pathogenesis of VAP, suggesting that microaspiration of contaminated oropharyngeal secretions might be the first step of the colonization of lower respiratory tract (10). Further, a large multicenter study was conducted in 449 adults requiring invasive mechanical ventilation for $>48 \mathrm{~h}$, and enteral nutrition to evaluate the non-inferiority of the absence of residual gastric volume monitoring, compared with measurement of gastric residual volume every $6 \mathrm{~h}$ (11). Intolerance to enteral nutrition was based only on regurgitation and vomiting in the intervention group and based on residual gastric volume greater than $250 \mathrm{~mL}$ at any of the 6 hourly measurements and regurgitation or vomiting in the control group. Whilst no significant difference was found in the incidence of VAP, other ICU-acquired infections, mechanical ventilation duration, ICU stay length, or mortality rates; the proportion of patients receiving $100 \%$ of their calorie goal was significantly higher in the intervention, compared with the control group. The results of this study suggest that the stomach might play a marginal role in the pathogenesis of VAP. However, the higher incidence of vomiting in intervention group 
suggests that microaspiration might have occurred more frequently in this group compared with control group. Therefore, another interpretation of the results could be that the higher proportion of patients who received a better nutrition support in the intervention group might have improved host defense against microaspirated bacteria. Previous studies have clearly shown a significant relationship between nutritional status and the risk for ICU-acquired infection (12). Recently, the results of the large randomized controlled multicenter trial NutriRéa 2 confirmed that enteral nutrition, compared with parenteral nutrition, was not associated with increased risk for $\operatorname{VAP}(13)$.

In spite of the questionable role of the stomach in the pathogenesis of VAP, preventive measures, other than those related to enteral nutrition, aiming at preventing microaspiration of gastric contents and oropharyngeal secretions should be performed in critically ill patients, as their risk factors are similar.

\section{Conclusions}

Microaspiration of gastric contents is common intubated in critically ill patients. Prevention of microaspiration of contaminated oropharyngeal and gastric secretions is helpful to prevent VAP. However, whilst enteral nutrition is a risk factor for vomiting and probably for microaspiration of gastric contents, its beneficial effects on nutritional status are probably more important for host defense than its side effects. Further studies should better investigate the impact of enteral nutrition on microaspiration of gastric contents, and its beneficial effects on the immune status of critically ill patients.

\section{Acknowledgements}

None.

\section{Footnote}

Conflicts of Interest: The authors have no conflicts of interest to declare.

\section{References}

1. Metheny NA, Clouse RE, Chang YH, et al.

Tracheobronchial aspiration of gastric contents in critically ill tube-fed patients: frequency, outcomes, and risk factors. Crit Care Med 2006;34:1007-15.

2. Jaillette E, Girault C, Brunin G, et al. Impact of taperedcuff tracheal tube on microaspiration of gastric contents in intubated critically ill patients: a multicenter clusterrandomized cross-over controlled trial. Intensive Care Med 2017;43:1562-71.

3. Nseir S, Zerimech F, Jaillette E, et al. Microaspiration in intubated critically ill patients: diagnosis and prevention. Infect Disord Drug Targets 2011;11:413-23.

4. Nseir S, Zerimech F, Fournier C, et al. Continuous control of tracheal cuff pressure and microaspiration of gastric contents in critically ill patients. Am J Respir Crit Care Med 2011;184:1041-7.

5. Brégeon F, Papazian L, Delpierre S, et al. Role of proinflammatory activity contained in gastric juice from intensive care unit patients to induce lung injury in a rabbit aspiration model. Crit Care Med 2008;36:3205-12.

6. Prod'hom G, Leuenberger P, Koerfer J, et al. Nosocomial pneumonia in mechanically ventilated patients receiving antacid, ranitidine, or sucralfate as prophylaxis for stress ulcer. A randomized controlled trial. Ann Intern Med 1994;120:653-62.

7. Reignier J, Darmon M, Sonneville R, et al. Impact of early nutrition and feeding route on outcomes of mechanically ventilated patients with shock: a post hoc marginal structural model study. Intensive Care Med 2015;41:875-86.

8. Drakulovic MB, Torres A, Bauer TT, et al. Supine body position as a risk factor for nosocomial pneumonia in mechanically ventilated patients: a randomised trial. Lancet 1999;354:1851-8.

9. Heyland D, Mandell LA. Gastric colonization by gramnegative bacilli and nosocomial pneumonia in the intensive care unit patient. Evidence for causation. Chest 1992;101:187-93.

10. Bonten MJ, Gaillard CA, van Tiel FH, et al. The stomach is not a source for colonization of the upper respiratory tract and pneumonia in ICU patients. Chest 1994;105:878-84.

11. Reignier J, Mercier E, Le Gouge A, et al. Effect of not monitoring residual gastric volume on risk of ventilatorassociated pneumonia in adults receiving mechanical ventilation and early enteral feeding: a randomized controlled trial. JAMA 2013;309:249-56.

12. Heidegger CP, Berger MM, Graf S, et al. Optimisation of energy provision with supplemental parenteral nutrition in 
critically ill patients: a randomised controlled clinical trial. Lancet 2013;381:385-93.

13. Reignier J, Boisramé-Helms J, Brisard L, et al. Enteral versus parenteral early nutrition in ventilated adults with

Cite this article as: Rouzé A, Jaillette E, Nseir S. Relationship between microaspiration of gastric contents and ventilatorassociated pneumonia. Ann Transl Med 2018;6(21):428. doi: 10.21037/atm.2018.07.36 shock: a randomised, controlled, multicentre, openlabel, parallel-group study (NUTRIREA-2). Lancet 2018;391:133-43. 